\title{
In-Vitro Quantitative Comparison of Platelet Rich Fibrin, and Plasma Rich in Growth Factor, with Age, Gender, Blood Parameters
}

\author{
Siddharth Narayan ${ }^{1}$, Sankari Malaiappan²
}

\author{
${ }^{1}$ Department of Periodontology, Saveetha Dental College, Saveetha University of Medical and Technical \\ Sciences, Chennai, Tamil Nadu, India. ${ }^{2}$ Department of Periodontology, Saveetha Dental College, Saveetha \\ University of Medical and Technical Sciences, Chennai, Tamil Nadu, India.
}

\section{ABSTRACT}

\section{BACKGROUND}

Periodontal therapy and its recent advances has modernised leaps and bounds with newer regenerative modalities in an attempt to regenerate bone, gingiva, periodontal ligament and cementum. One of the newly accepted trends in regenerative therapy is the use of platelet concentrates such as platelet rich fibrin, plasma rich in growth factor which act as biological scaffold, fillers as well a vehicle along with bone grafts. Platelet concentrates have been found to be rich in growth factors and are used in the field of periodontology as an additive to bone grafting in sites of bony defects as a potential filler material. We wanted to evaluate the relation between the volume of blood extracted and weight of corresponding platelet rich fibrin and plasma rich in growth factor, and correlation of weight of platelet rich fibrin and plasma rich in growth factor with age, gender and blood parameters.

\section{METHODS}

A sample of 36 systemically healthy patients was randomly selected from the outpatient department of a dental college in Chennai. They were matched for age, gender and distributed into two broad groups: one for PRF and the other for PRGF comprising 9 females and 9 males in each group. A routine complete blood count including red blood cell count, white blood cell count and platelet count and haemoglobin were determined.

\section{RESULTS}

There was no relation between the weight of platelet rich fibrin and plasma rich in growth factor and the gender or age of the patient. There was also no apparent correlation between the platelet count and the platelet weight obtained. In some patients despite high platelet concentration, substantial PRF or PRGF weight was not obtained.

\section{CONCLUSIONS}

Within the limits of this study, it was found that the quantity of PRF and PRGF obtained is independent of age, and gender with no direct relation between the RBC count, WBC count, and haemoglobin.

\section{KEY WORDS}

Age, Attachment Loss, Biochemical Comparison, Periodontal, PRF, PRGF, Weight
Corresponding Author: Dr. Siddharth Narayan. No 112 Boys hostel, Saveetha Dental College, Poonamallee 600077, Channai, Tamil Nadu, India. E-mail: dr.siddharthnarayan@gmail.com

DOI: $10.14260 /$ jemds/2020/570

How to Cite This Article:

Narayan $S$, Malaiappan S. In-vitro quantitative comparison of platelet rich fibrin and plasma rich in growth factor with age, gender, blood parameters. J Evolution Med Dent Sci 2020;9(36):2620-2624, DOI: $10.14260 / \mathrm{jemds} / 2020 / 570$

Submission 30-10-2019,

Peer Review 01-08-2020,

Acceptance 07-08-2020,

Published 07-09-2020.

Copyright (C) 2020 JEMDS. This is an open access article distributed under Creative Commons Attribution License [Attribution 4.0 International (CC BY 4.0)] 


\section{BACKGROUND}

Biomimetic is an interdisciplinary field in which principles of engineering, chemistry and biology are applied to the synthesis of materials, synthetic systems or machines that have functions that mimic biological processes. Their commercial applications include regenerative medicine, local drug delivery and tissue engineering. ${ }^{1}$ platelet rich fibrin are autologous white blood cells and platelets preferred from patients own blood with potential for regeneration in gingival recession management as well as a transient membrane for bone grafting in intrabony defects apart from its routine role as a biological filler without any adverse effects platelet concentrates have been used in medicine routinely for a long period of time in the field of Orthopaedics, but since the discovery of methods of preparation of platelet rich Fibrin by Choukroun et $\mathrm{al}^{2}$ in France 2001 and Application of Plasma Rich in Growth factors in Oral Surgery by Anitua E in 2001,3 it has been constantly applied in Dentistry. They are the first of all blood extracts obtained primarily through centrifugation, applied for topical and infiltrative purposes. ${ }^{2}$ Their prime purpose emerged as biological fillers with a lifespan of that of platelets around 7 days currently used extensively in oral and maxillofacial surgery as well as periodontology.

A classification was proposed in 2009 based on the presence of Cell content and Fibrin architecture 4 which includes I - Leukocyte poor platelet Rich Plasma, II - Leukocyte and platelet Rich Plasma, III - Leukocyte poor platelet Rich Fibrin and IV - Leukocyte and platelet Rich Fibrin. Platelet rich Fibrin and Plasma rich in growth Factor have extensively been used in the field of Periodontology and Oral and Maxillofacial Surgery as an alternative as well as an additive to bone grafting in sites of Bony defects as a potential filler material to stimulate, and enhance healing. 4 , PRF because of its Gelatinous nature, along with the ease of handling and procurement has always been seen as an advantage over PRGF in terms of handling and surgical placement into desired sites.

Considering the extensive application of both these materials in the future of periodontology and the fact that no studies have tried to correlate the volume of blood, weight of PRF and PRGF, with biochemical parameters, age and gender, this study was undertaken.

\section{METHODS}

The present study was initiated after ethical committee approval from Dental College and University (SRB/SDMDS11/18/PERIO/02) with an In-vitro design. After obtaining informed written consent from all patients involved in this study especially pertaining to the use of their blood parameters for scientific and research related purposes only.

A sample of 36 systemically healthy patients was randomly selected from the outpatient of a dental college in Chennai, as prior studies assessing quantity and quality of PRF used a sample size ranging from 6 to 24. Included patients were then matched for age, gender and distributed into two broad groups: one for PRF and the other for PRGF comprising 9 females and 9 males each.
All the samples were then made to take a routine complete blood count including red blood cell count, white blood cell count and platelet count with along with haemoglobin. The results for the Complete Blood count were measured by a Haematology Analyzer.

\section{Preparation of PRF}

The protocol employed for preparation of PRF was given by Choukroun et al, ${ }^{1}$ where $5 \mathrm{ml}$ of blood was collected from each patient using a disposable Needle and syringe without any anticoagulant and centrifuged at $3000 \mathrm{rpm}$ for 10 minutes using a tabletop centrifuge.

\section{Preparation of PRGF}

The protocol employed for preparation of PRGF 8 included collection of $5 \mathrm{ml}$ of blood collected from the patients which was then added to $3.8 \%$ Sodium citrate centrifuged at $460 \mathrm{G}$ for 8 minutes using a tabletop centrifuge. The blood sample separated into different fractions: the upper fraction of about $1 \mathrm{cc}$ was plasma poor in Growth Factor, the middle $0.5 \mathrm{cc}$ was plasma average in growth factor, the remaining $0.5 \mathrm{cc}$ exactly over the red blood cells was plasma rich in growth factor, which was collected.

\section{Quantitative Analysis for Both PRF and PRGF}

From the obtained samples, PRF was separated from remaining blood cells using a No. 5-6 Gracey`s curette** such that minimal PRF was lost during the RBC plug separation. The PRF was weighed by placing it in a $10 \mathrm{ml}$ beaker whose weight was pre-recorded and subtracted from all obtained values. The remaining blood pigments were also weighed.

A similar procedure was also followed for weighing the PRGF, where the top $1.5 \mathrm{cc}$ of plasma obtained was separated using a 100-microliter micro pipette. The remaining $0.5 \mathrm{cc}$ present directly over the red blood cells was then collected and was weighed by placing it in a $10 \mathrm{ml}$ beaker whose weight was pre-recorded and subtracted from all obtained values. The remaining blood pigments were also weighed.

All weight measurements from PRF and PRGF were recorded using a Mettler`s Digital Analytical Scale with a readability of $0.1 \mathrm{mg}$.

\section{Statistical Analysis}

All values collected were analysed using SPSS version 23 (Statistical Package for the Social Sciences, Norman H. Nie, C. Hadlai Hull and Dale H). Statistical significance with $\mathrm{p}$ value less than 0.05 was considered to be statistically significant. Anova was used to assess statistical significance intragroup while Mann Whitney $U$ test was used to assess intergroup statistical significance between PRF and PRGF groups, Chi square test was used for age alone. (Table 1) All blood parameters, counts, between both groups were considered statistically insignificant $(\mathrm{p}>0.05)$ since platelet weight, remaining blood weight and total blood weight were statistically significant $(\mathrm{p}<0.05)$ on inter group analysis and intragroup analysis, these findings were considered insignificant. 


\section{RESULTS}

\section{Demographic Data}

It was interesting to observe that there was no relation between the weight of platelet rich fibrin and plasma rich in growth factor and the gender or age of the patient. This could imply gender and age have no influence on the quantity of PRF and PRGF but further studies have to be carried out regarding the Quality of obtained PRF and PRGF. (Figure 1)

The other apparent findings include variation between the volume of blood extracted and the platelet weight obtained. This could imply drawing more blood does not imply a proportionate increase in the amount of PRF or PRGF obtained. There was no apparent correlation between the platelet count and the platelet weight obtained, in some patients despite high platelet concentration substantial PRF or PRGF weight was not obtained. Previous studies have shown, at lower platelet concentrations the effect of PRP was suboptimal while higher concentrations might have a paradoxical inhibitory effect. 8,9 (Table 2, Figure 2)

Despite standardisation of the quantity of blood collected from each sample and the procedure followed for each sample, there was no consistent remaining blood pigment weight and platelet rich fibrin (or) plasma rich in growth factor.

\section{Biochemical Parameters}

Comparison of RBC count, WBC count, platelet count with platelet weight, remaining blood cell weight and total weight of sample, age of patients from whom sample was collected for both PRGF and PRF.

Data from the present study shows that age of patients (years) in PRF, PRGF group along with their RBC count (million per cubic $\mathrm{mm}$ ), WBC count (thousand per cubic $\mathrm{mm}$ ) platelet count (lakh per cubic $\mathrm{mm}$ ) which were found to be statistically insignificant between groups and intragroup ( $p>0.05)$. Mean platelet weight $(\mathrm{mg})$ remaining blood weight $(\mathrm{mg})$ and mean total weight $(\mathrm{mg})$ between groups were found to be significant using Mann Whitney U test ( $\mathrm{p}<0.05)$, considered statistically significant while intra group were found to be statistically significant using Anova $(\mathrm{p}<0.05)$.

\begin{tabular}{|c|c|c|c|c|c|}
\hline SI. No. & Features & $\begin{array}{l}\text { Values from } \\
\quad \text { PRF } \\
\text { (Mean } \pm \text { S.D.) }\end{array}$ & $\begin{array}{l}\text { Values from } \\
\quad \text { PRGF } \\
\text { (Mean } \pm \text { S.D.) }\end{array}$ & $\begin{array}{l}\text { Mann } \\
\text { Whitney } \\
\text { U Test }\end{array}$ & Anova \\
\hline $\mathbf{0}$ & Gender & $\begin{array}{c}9 \text { Males } \\
9 \text { Females }\end{array}$ & $\begin{array}{l}9 \text { Males } \\
9 \text { Females }\end{array}$ & & \multirow{2}{*}{-NA- } \\
\hline 1 & Mean Age (Years) & $27 \pm 5.35$ & $32.11 \pm 10.28$ & $\begin{array}{c}0.155 \\
\text { (Chi } \\
\text { square) }\end{array}$ & \\
\hline 2 & $\begin{array}{c}\text { Mean RBC Count } \\
\text { (million per cubic } \mathrm{mm} \text { ) }\end{array}$ & $4.92 \pm 0.53$ & $4.68 \pm 0.67$ & 0.093 & 0.101 \\
\hline 3 & $\begin{array}{l}\text { Mean WBC Count } \\
\text { (thousand per cubic } \mathrm{mm} \text { ) }\end{array}$ & $9.37 \pm 2.09$ & $8.35 \pm 1.40$ & 0.146 & 0.136 \\
\hline 4 & $\begin{array}{l}\text { Mean platelet Count } \\
\text { (lakh per cubic mm) }\end{array}$ & $2.81 \pm 0.59$ & $2.58 \pm 0.45$ & 0.561 & 0.353 \\
\hline 5 & $\begin{array}{l}\text { Mean platelet weight } \\
\text { (mg) }\end{array}$ & $0.93 \pm 0.14$ & $0.66 \pm 0.33$ & $0.003^{*}$ & $0.018^{* *}$ \\
\hline 6 & $\begin{array}{l}\text { Mean remaining blood } \\
\text { cells weight }(\mathrm{mg})\end{array}$ & $4.36 \pm 0.77$ & $3 \pm 0.64$ & $0.000^{*}$ & $0.000^{* *}$ \\
\hline 7 & Mean total weight (mg) & $5.18 \pm 0.85$ & $3.64 \pm 0.75$ & $0.000^{*}$ & $0.000^{* *}$ \\
\hline \multicolumn{6}{|c|}{$\begin{array}{c}\text { Table 1. Data Comparing the Mean RBC Count, Mean WBC Count, } \\
\text { Mean platelet Count, Mean platelet Weight, Mean Remaining } \\
\text { Blood Cell Weight, Mean Age, Gender, Mean Total Weight } \\
\text { from PRGF and PRF Groups }\end{array}$} \\
\hline
\end{tabular}

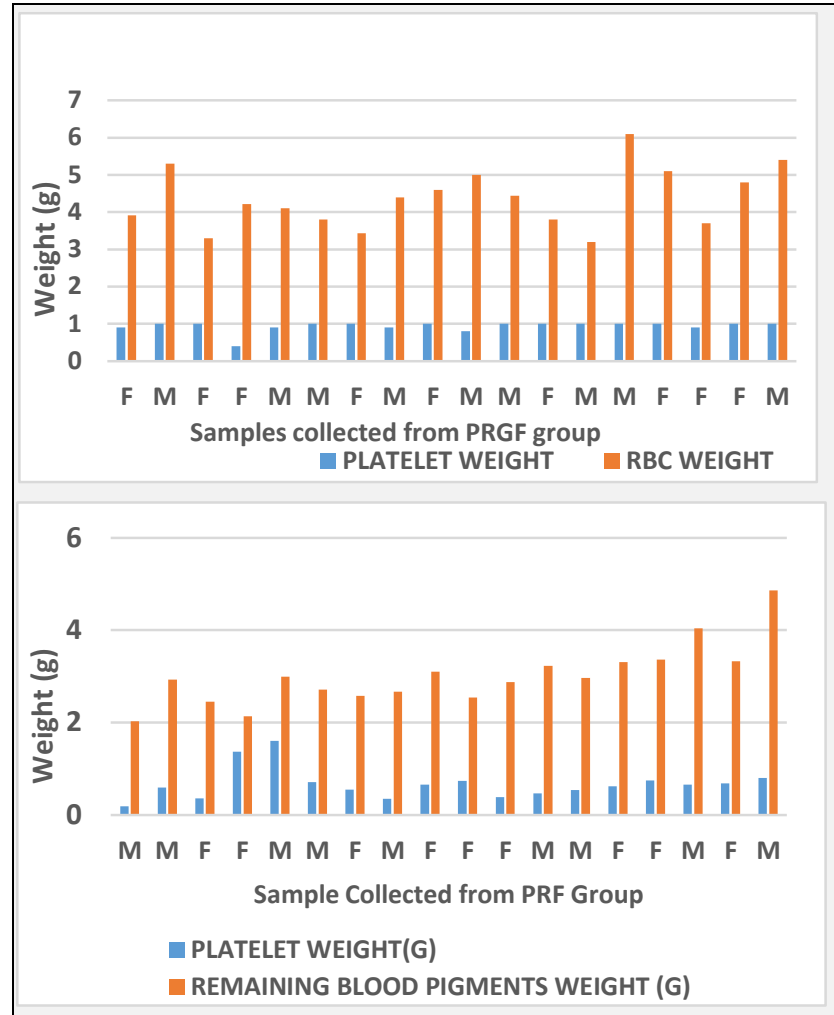

Figure 1. Comparing platelet Weight and Remaining Blood Weight with Gender of Sample Collected from PRGF, PRF

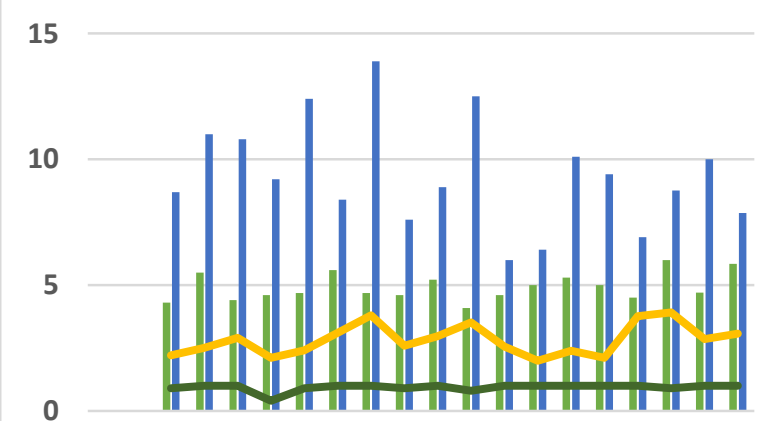

$\begin{array}{lllllllllll}1 & 2 & 3 & 4 & 5 & 6 & 7 & 8 & 9 & 1011 & 121314151617181920\end{array}$ SAMPLE COLLECTED FOR PRGF

RBC COUNT (million/ cumm)

WBC COUNT (thousand/cumm)

PLATELET COUNT (lakh/cumm)

$\longrightarrow$ PLATELET WEIGHT (g)

15

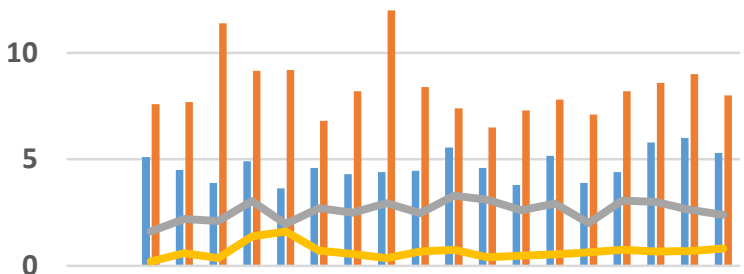

$\begin{array}{lllllllllll}1 & 2 & 3 & 4 & 5 & 6 & 7 & 8 & 9 & 1011 & 121314151617181920\end{array}$ SAMPLE COLLECTED OR PRF

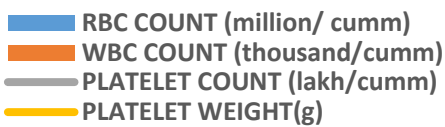

Figure 2. Comparison of RBC Count, WBC Count, platelet Count with platelet Weight from the Sample Collected from PRGF, PRF 


\section{DISCUSSION}

Studies have been done comparing the qualitative and quantitative aspects of platelet rich fibrin and platelet rich plasma. However, no studies have directly compared platelet rich fibrin and plasma rich in growth factor.

Weight is a fundamental and important description of an object which unlike other measurements of an object is not influenced by its shape, while volume is the most commonly used measure in terms of extraction of body fluids such as blood and saliva. The relation mass per unit volume is defined as density which was originally given by Archimedes. The Application of PRF and PRGF as a glue or filler material, obtained from a series of events in the cascade of coagulation and the initial matrix of Healing represents a Biological Surgical Adjuvant with widespread clinical uses.

Initially it was though that PRF does not contain high concentration of growth factors which was recently proven incorrect as PRF and its derivatives concentrated growth factor contain large amounts of growth factors.10,11 Prior studies have shown superiority of PRF over PRP for periodontal management of osseous defects suggesting various explanations such as the Gelling mode. This Gelling mode occurs natural and slowly without the addition of any foreign agent for polymerisation which establishes a 3-D organisation of Fibrin Network effectively functioning as a Cellular Threshold ${ }^{1}$ Apart from the easier surgical handling of PRF, a gel over PRGF which is a liquid while both show similar High concentrations of Growth Factors. ${ }^{12}$ The ultimate goal associated with the use of such materials and Periodontal Therapy was the replacement of supporting apparatus by regeneration of cementum, periodontal ligament and alveolar bone. 13,14

The key aim of this study was to compare the physical nature of the PRF and PRGF using weight as a parameter to that of its biological concentration of platelets. All the Biological concentration including RBC count, WBC count and platelet count were measured using an automated cell count system as it proves to be more precise and less time consuming. ${ }^{15}$ The accuracy and standardisation of Mettlers Digital Analytical scale and the Pipettes used checked manually prior to usage as per Laboratory Balance protocols.

There was no apparent correlation between the volume of blood extracted and the platelet weight obtained which would suggest the assumption drawing more blood does not imply a proportionate increase in the amount of PRF or PRGF obtained, so if $5 \mathrm{ml}$ of Blood gave $2 \mathrm{~g}$ it does not imply that 10 $\mathrm{ml}$ would give $4 \mathrm{~g}$ it could be as low as $3 \mathrm{~g}$ or as high as $7 \mathrm{~g}$. The significance of this finding is only apparent when applied to a patient with multiple Bone defect, where larger quantities of PRF or PRGF are required to fill more number of defect. There was no apparent co relation between the platelet count and the platelet weight obtained. So even when a patient had a high platelet Count such as 3 lakh per cubic millimetres of blood the weight of PRF obtained might be $1.37 \mathrm{~g}$, while a platelet count of 1.96 lakh per cubic millimetres of blood gave a platelet weight of $1.6 \mathrm{~g}$. The platelet count is a quantity but has been accepted as one of the major indexes for ensuring the quality of platelet concentrates.16 However there have been very few methods to determine platelet count in gel types of platelet concentrations, thus this study used platelet counts obtained from the blood sample itself using an Automated Cell counters rather than the technique sensitive "Subtraction Method" discussed later. ${ }^{17}$

Despite standardisation of the quantity of blood collected from each sample and the procedure followed for each sample, there was no consistent remaining blood pigment weight and platelet rich fibrin (or) plasma rich in growth factor. In some patients though the weight of PRF obtained was relatively 0.59 $\mathrm{g}$ and $0.71 \mathrm{~g}$ it did not account for more than $17 \%$ and $20 \%$ of the net weight of the sample while in others where the PRF weight was $1.37 \mathrm{~g}$ and $1.6 \mathrm{~g}$ but accounted for only $39 \%$ and $35 \%$ of net weight of the sample. In context to the above mentioned findings, another factor Therapeutic Autologous platelet concentration was given by Marx R.E where approximately 1 million platelets / microliter in Patients considering whole blood contains approximately 2,00,000 + or - 75,000 platelets / microliter plays an important role in obtaining therapeutic platelet concentrations. ${ }^{18}$ Based on these findings an assumption could be made that different blood vessels have different concentration of Blood which constantly keep varying, at one given point of time if a high concentration of platelets was present in a blood vessel and at that very point if blood was extracted from it, sufficient quantity of PRF or PRGF required for surgical application could be obtained with lesser extraction of volume of Blood.

The limitations of the above study includes, the method to procure PRGF always ensures that a constant weight of PRGF was always obtained as the $0.5 \mathrm{cc}$ of plasma removed exactly above the red blood cells was always weighed in case of Plasma Rich in Growth Factor, while PRF values were more prone to vary from one person to another. A more accurate method for Estimation of platelet Counts in PRF and PRF like clots is a "Subtraction method" where subtracting platelet count in the clot exudate, supernatant serum, and in the red blood cell fraction from platelet counts in the initial wholeblood sample. ${ }^{17,19}$ However even this methods has not been able to entirely account for loss of platelets. The sample size was not large enough to be descriptive of an entire population despite statistical significance which was calculated and thus further studies using a larger sample size would be required to verify the above findings.

\section{CONCLUSIONS}

It was found that the Quantity of PRF and PRGF obtained is independent of age and gender. However, it did not compare the Quality of PRF and PRGF obtained. The above findings also suggest no direct relation between the RBC count, WBC count and Haemoglobin with the quantity of PRF and PRGF obtained. An increased platelet count did not increase the weight of PRF and PRGF obtained. However, further studies with a larger sample should be performed to verify these findings.

Financial or Other Competing Interests: None.

\section{REFERENCES}

[1] Bhushan B. Biomimetics: lessons from nature--an overview. Philos Trans A Math Phys Eng Sci 2009;367(1893):1445-86. 
[2] Dohan DM, Choukroun J, Diss A, et al. Platelet-rich fibrin (PRF): a second-generation platelet concentrate. Part I: technological concepts and evolution. Oral Surg Oral Med Oral Pathol Oral Radiol Endodontol 2006;101(3):e37-44.

[3] Anitua E, Alkhraisat MH, Orive G. Perspectives and challenges in regenerative medicine using plasma rich in growth factors. J Control Release 2012;157(1):29-38.

[4] Ehrenfest DMD, Rasmusson L, Albrektsson T. Classification of platelet concentrates: from pure plateletrich plasma (P-PRP) to leucocyte- and platelet-rich fibrin (L-PRF). Trends Biotechnol 2009;27(3):158-67.

[5] Panda S, Ramamoorthi S, Jayakumar ND, et al. Platelet rich fibrin and alloplast in the treatment of intrabony defect. J Pharm Bioallied Sci 2014;6(2):127-31.

[6] Kawabata H, Isobe $\mathrm{K}$, Watanabe $\mathrm{T}$, et al. Quality assessment of platelet-rich fibrin-like matrix prepared from whole blood samples after extended storage. Biomedicines 2017;5(3):57.

[7] Kitamura Y, Watanabe T, Nakamura M, et al. Platelet counts in insoluble platelet-rich fibrin clots: a direct method for accurate determination. Front Bioeng Biotechnol 2018;6:4.

[8] Lekovic V, Camargo PM, Weinlaender $\mathrm{M}$, et al. Effectiveness of a combination of platelet-rich plasma, bovine porous bone mineral and guided tissue regeneration in the treatment of mandibular grade II molar furcations in humans. J Clin Periodontol 2003;30(8):746-51.

[9] Weibrich G, Hansen T, Kleis W, et al. Effect of platelet concentration in platelet-rich plasma on peri-implant bone regeneration. Bone 2004;34(4):665-71.

[10] Lundquist R, Dziegiel MH, Agren MS. Bioactivity and stability of endogenous fibrogenic factors in platelet-rich fibrin. Wound Repair Regen 2008;16(3):356-63.
[11] Su CY, Kuo YP, Tseng YH, et al. In vitro release of growth factors from platelet-rich fibrin (PRF): a proposal to optimize the clinical applications of PRF. Oral Surg Oral Med Oral Pathol Oral Radiol Endodontol 2009;108(1):5661.

[12] Piemontese M, Aspriello SD, Rubini C, et al. Treatment of periodontal intrabony defects with demineralized freezedried bone allograft in combination with platelet-rich plasma: a comparative clinical trial. J Periodontol 2008;79(5):802-10.

[13] Graves DT, Cochran DL. Mesenchymal cell growth factors. Crit Rev Oral Biol Med 1990;1(1):17-36.

[14] Döri F, Huszár T, Nikolidakis D, et al. Effect of platelet-rich plasma on the healing of intra-bony defects treated with a natural bone mineral and a collagen membrane. J Clin Periodontol 2007;34(3):254-61.

[15] Salinas M, Rosas J, Iborra J, et al. Comparison of manual and automated cell counts in EDTA preserved synovial fluids. Storage has little influence on the results. Ann Rheum Dis 1997;56(10):622-6.

[16] Kenner T. The measurement of blood density and its meaning. Basic Res Cardiol 1989;84(2):111-24.

[17] Aggarwal A, Singhal N. Evaluation of content and disturbution of platelets in platelet rich in fibrin at various centrifugation time periods: a light microscopic study. Int J Dent Med Res 2015;1:61-4.

[18] Marx RE. Platelet-rich plasma: evidence to support its use. J Oral Maxillofac Surg 2004;62(4):489-96.

[19] Eren G, Gurkan A, Atmaca H, et al. Effect of centrifugation time on growth factor, and MMP release of an experimental platelet-rich fibrin type product. Platelets 2016;27(5):427-32. 